\title{
Escolas como postos de socorros: instituições escolares na epidemia de gripe espanhola no Rio de Janeiro (1918)
}

Schools as Aid Stations: School Institutions in the Spanish Flu Epidemic in Rio de Janeiro (1918)

Ademir Valdir Santos*

\section{RESUMO}

A investigação objetiva identificar impactos da disseminação da gripe espanhola em instituições escolares da cidade do Rio de Janeiro em 1918 e discutir as transformações que ocorreram na organização institucional. Trata-se de pesquisa documental, que utiliza edições do jornal Correio da Manhã, analisadas com base em pesquisas sobre aquela epidemia e em bibliografia da História da Educação, principalmente do campo teórico-metodológico da História de Instituições Escolares. Os resultados assinalam que, inicialmente, várias unidades foram fechadas. Mas revelam, sobretudo, que instituições escolares de diversos tipos foram transformadas em postos de socorros, incorporando mudanças na sua finalidade social. Mostram também que as condições de enfrentamento da epidemia da gripe espanhola exigiram novas ações dos sujeitos educativos, principalmente dos professores, que assumiram protagonismo na prevenção e no atendimento à saúde da população.

Palavras-chave: História da Educação; Instituições Educativas Brasileiras; Saúde e Educação.

\section{Abstract}

The investigation aims to identify the impacts of the spread of the Spanish flu in school institutions in the city of Rio de Janeiro in 1918, and to discuss the transformations that occurred in the institutional organization. This is a documentary research which uses editions of the newspaper Correio da Manhã, analyzed based on researches on that epidemic and on the bibliography of the History of Education, mainly from the theoreticalmethodological field of the History of School Institutions. The results indicate that, initially, several units were closed. But they reveal, above all, that school institutions of different types have been transformed into health help posts, incorporating changes in their social purpose. And they also show that the conditions for facing the Spanish flu epidemic demanded new actions from educational subjects, mainly from teachers, who assumed a leading role in the prevention and care of the population's health.

Keywords: History of Education; Brazilian Educational Institutions; Health and Education.

\footnotetext{
* Universidade Federal de Santa Catarina (UFSC), Florianópolis, SC, Brasil. ademirvaldirdossantos@ gmail.com <https://orcid.org/0000-0002-5958-689X>
} 
24 de dezembro de 1918, véspera do Natal. Na cidade do Rio de Janeiro, capital brasileira, notícias sobre a gripe espanhola ainda ecoavam na imprensa escrita local. O Correio da Manhã destacava os dados apresentados pelo Ministério do Interior aos deputados, sob o título "As victimas da grippe. Informações prestadas á Camara":

As informações prestadas pelo medico demographista da Saude Publica registraram 14.104 obitos para o período que vae de 12 de outubro a 8 de novembro do fluente anno, sendo que 10.323 se deram na zona urbana; 3.740 na suburbana, e 41 a bordo do Pittsburg.

Quanto ao registro de obitos, informa a Saude Publica não ser da sua alçada, mas sim da magistratura local. Não se preoccupou aquella repartição com essa formalidade, recebendo os attestados de differentes officiaes sem declaração alguma de que o respectivo obito não tivesse sido registrado.

[...] muitas das primeiras vias de attestados de obito permanecem ainda na Santa Casa...

[...] No que toca aos suburbios, a Saude Publica informa que dos 3.740 obitos, 887 deixaram de ser registrados (As Victimas da grippe, 1918, p. 3).

Embora pudesse tratar de números ainda imprecisos quanto às mortes, $\mathrm{o}$ teor do jornal carioca evidencia a gravidade da situação. O periódico Correio da Manhã, um dos mais lidos do país, vinha publicando, desde fins de setembro, uma variedade de matérias sobre la dansarina; denominação irônica para o mal que teria surgido na Espanha. A partir de então, narrativas inusitadas sobre a doença eram presença diária na folha, compartilhando o espaço gráfico com os relatos sobre a I Guerra Mundial, o que mesclava aspectos de tragédias contemporâneas. Destarte, localizei, em notícia de 22 de setembro, um dos primeiros informes sobre uma forte "grippe" entre a tripulação do $L a$ Plata; um navio brasileiro em missão médica que aportara em Dakar, na costa africana - um importante ponto de confluência de embarcações, onde a "hespanhola" espreitava. O porto senegalês seria o epicentro da doença, e os primeiros cidadãos brasileiros contaminados estavam in mare, distantes da pátria.

Quase todos os vapores que chegam da Europa trazem agora noticias alarmantes de uma molestia de caracter epidêmico [...]. 
Trata-se da "influenza hespanhola", que tem ceifado quasi fulminantemente innumeras vidas. Os telegrammas que vêm de Hespanha e de Portugal se referem veladamente ao mal, que reina especialmente em portos do Mediterraneo, estendendo-se ainda e tendo já attingido varios portos da costa africana.

[...] a "influenza", que na Hespanha também cognominaram "la dansarina”, victimou só em Madrid, há dois ou tres mezes, cerca de 600 pessoas, das quaes a maior parte pertencia á própria classe medica (A "Influenza Hespanhola" irrompeu..., 1918, p. 1).

E foi por desventura semelhante que a doença aportou no Brasil, cruzando o Atlântico. De acordo com a edição do dia seguinte, o paquete de bandeira britânica Demerara trouxe a "nova peste" ao Rio de Janeiro: "Domingo ultimo, chegou, completamente infeccionado desse terrivel morbus, o paquete inglez 'Demerara', a cujo bordo se deram seis obitos, tendo aqui, desembarcado alguns outros enfermos desse mal, conforme noticiámos". O texto ainda denuncia os poucos cuidados das autoridades sanitárias portuárias, pois dois desembarcados teriam morrido; um na Santa Casa e outro em sua residência (Dos influenzados do Demerara..., 1918, p. 3). Eram os primeiros "hespanholados".

Dada essa contextualização, objetivo identificar impactos da doença nas instituições educativas da cidade do Rio de Janeiro em 1918, e, de modo associado, analisar as transformações que ocorreram na organização escolar devido à moléstia. Quanto à metodologia, se trata de uma pesquisa documental, cujas fontes são edições do jornal Correio da Manhã, analisadas com base em bibliografia associada à História de Instituições Escolares e à situação epidêmica, conjugando referenciais sobre a educação formal àqueles da saúde pública. Ao optar pela imprensa como fonte e objeto de pesquisa, ratifico as afirmações de Bastos (2002, p. 152): "Nesta perspectiva, a imprensa cria um espaço público através do seu discurso - social e simbólico - agindo como mediador cultural e ideológico privilegiado entre o público e o privado, fixa sentidos, organiza relações e disciplina conflitos."

O texto está estruturado em quatro partes. Após esta introdução, a seção seguinte apresenta a chegada da gripe espanhola ao Rio de Janeiro, reunindo aspectos sobre a conformação da epidemia e as medidas para combatê-la. Logo após, trato dos impactos da doença em escolas do Rio de Janeiro. Neste momento, também escrutino as alterações no funcionamento das instituições 
escolares, discutindo transformações em sua finalidade social. Por último, seguem as considerações finais.

\section{ALEA JACTA EST, OU VENHA O QUE VIER! A GRIPE ESPANHOLA NA CIDADE DO RIO DE JANEIRO}

Os primeiros relatos sobre a gripe espanhola são controversos. Exemplo disso é uma matéria de capa do Correio da Manhã que traz, lado a lado, as palavras de Carlos Chagas e do diretor geral da Saúde Pública, Carl Seidl. O primeiro, um cientista reconhecido devido às pesquisas sobre a malária e a tripanossomíase americana; esta denominada "doença de Chagas" para homenageá-lo. O infectologista se pronunciou quanto à recém-chegada enfermidade e destacou a necessidade de prevenção, embora afirmando que não era possível emitir um parecer mais sólido:

- Necessario, se torna que, desde já, seja tomadas differentes medidas pelo Governo, entre as quaes a de desinfectar com o maior cuidado todos os navios procedentes da Europa, da zona em que se diz ser oriunda a perigosa moléstia, assim como proceder a rigorosa fiscalisação entre os respectivos passageiros, cujas roupas e bagagens deverão ser, também, convenientemente desinfectadas.

[...] na falta quasi absoluta de conhecimento do assumpto, o que posso adiantar sobre a nova epidemia para muitos nada mais senão a "grippe", denominada "influenza hespanhola" (A "Influenza Hespanhola" irrompeu..., 1918, p. 1).

Quanto ao doutor Seidl, falou de um rigoroso inquérito no Demerara. E que, apesar dos riscos da viagem, dos adoecimentos e até mesmo das mortes, somente um caso foi associado à influenza, o que era tranquilizador. Mesmo assim, quanto à chegada da doença ao Rio de Janeiro, o serviço de saúde faria tudo para que ela não acontecesse.

Quando aportou no Rio, há dois dias, o "Demerara", tive occasião de não ver confirmadas suspeitas que surgiram. Fui pessoalmente a bordo, examinei os livros do registro, conferenciei com o medico do navio, indaguei quanto pude e fiquei convencido de que não havia motivos de intranqüilidade, porquanto basta refletir que, em um paquete trazendo um mez de viagem nas peores condições moraes, pelos sustos da navegação actualmente, e deficientes condições materia- 
es, dentre 562 passageiros de $3^{\text {a }}$. classe enfermaram poucos e só falleceram cinco, entre creanças e adultos.

Desses cinco, um apenas teve o diagnostico de influenza. [...] precauções foram tomadas, no caso do "Demerara".

[...] o serviço sanitario que dirijo fará tudo quanto puder por evital-o (A "Influenza Hespanhola" irrompeu..., 1918, p. 1).

Apesar das declarações do diretor, o teor das notícias posteriormente publicadas sobre a sua atuação contra a epidemia é desabonador: "A epidemia de 'grippe' continúa a assolar o Rio de Janeiro, tomando as proporções de verdadeiro flagello", acrescido da afirmativa de que "Não querendo contrariar o dr. Carlos Seidl, cada vez mais convencido de que o 'mal não tem importancia', o governo nomeou um superintendente do serviço especial de combate á epidemia" (A Epidemia de "Grippe”..., 1918b, p. 1). Entremeada por adjetivação contundente, a escrita descreve a calamidade a que a epidemia conduziu a capital: "A cidade offerece um aspecto sepulchral. Com o fechamento de inumeras casas commerciaes, [...] a invasão das pharmacias por uma freguezia anciosa, que as enchia de um silencio de morte e de uma anciedade dolorosa, o Rio, hontem, mais parecia uma necrópole" (A epidemia de "grippe"..., 1918b, p. 1). E, diante do quadro, uma das pautas destacada é a demissão de Seidl (A Demissão do Dr Seidl, 1918, p. 1). Portanto, ao cotejar esses dados com outros estudos, verifico que, a partir de então, a administração da crise foi liderada por dois atores reconhecidos entre as elites médicas e políticas: “[...] Fernando Magalhães e Carlos Chagas assumiram o controle médico da cidade" (Barreto, 2015, p. 198). Entrou em cena a “Comissão Chagas".

Acompanhemos outras notícias sobre a epidemia, embasadas por publicações do Correio da Manhã. Inicialmente, verifica-se que a gripe atingiu diferentes estabelecimentos no mapa citadino, e que significativa parcela dos enunciados é relacionada às atividades de navegação, pois a moléstia seguiu adentrando por via portuária: infectados chegavam nos navios estrangeiros, como os seis marinheiros ingleses do Royal Transport, depois internados na Santa Casa, assustando funcionários e outros pacientes (Os Marinheiros do "Royal Transport"..., 1918, p. 4). Aliás, registros similares se acumulavam: 100 doentes no New Castle, um cruzador inglês; dois funcionários de uma embarcação dos Correios atacados pela influenza; três tripulantes do Aymoré adoeceram; na frota do Lloyd Brasileiro, a gripe se espalhou em seis vapores; o ministério da Marinha determinou 
que o encouraçado Minas Geraes, o aviso-faroleiro Tenente Lahmeyer e os navios de guerra das imediações se dirigissem à Ilha Grande para a quarentena (A "grippe" nos nossos quarteis..., 1918a, p. 3).

Noticiou-se, ainda, que, em apenas dois dias, surgiram 190 casos nos $1^{\circ} \mathrm{e}$ $2^{\circ}$ regimentos, e outros 60 na artilharia costeira, considerando-se espantosa a quantidade de praças e oficiais atacados pela influenza, que causou baixas entre os aquartelados da Vila Militar (A "Grippe" nos nossos quarteis..., 1918b, p. 3). Adiciono outros dados: pelo menos mil soldados estavam sendo atendidos no Hospital Central do Exército, onde faltavam camas e foi preciso colocar colchões no chão das enfermarias. Dia após dia, apareciam infectados nas fileiras do Exército, destacando-se 60 no 56 batalhão de caçadores, que elevaram para 494 os atendidos no Hospital do Exército, implicando na determinação, por parte do general chefe do corpo de Saúde, de que os gripados ficassem nos quartéis. Enfim, a doença atingiu fortalezas, fortes e batalhões, o que requisitou operações de desinfecção das instalações pelos próprios militares e reforçou a demanda por medicação, farmacêuticos e médicos (A "Grippe" nos nossos quarteis..., 1918a, p. 3).

Ambientes como fábricas, comércios, repartições públicas e prestadores de serviços em geral foram atingidos. Na Ilha da Conceição, por exemplo, 200 operários da Wilson Sons \& Co. foram encaminhados para o hospital São João Batista, enquanto 36 trabalhadores da Casa da Moeda abandonaram o serviço (A "grippe" nos nossos quarteis e o Estado..., 1918c, p. 3). Dentre o rol dos "hespanholados", constam operários, um deputado e sua mulher, funcionários do Posto Central de Assistência e da Alfândega, homens do Batalhão Naval, trabalhadores da Central do Brasil, um preso da delegacia do $25^{\circ}$ distrito, operários da Estrada de Ferro Central, o proprietário e diversos funcionários de uma panificadora em Madureira, quatro praças do $22^{\circ}$ distrito de Olaria, o escrivão e o comissário da delegacia do $23^{\circ}$ distrito de Madureira, o eletricista do Jockey Club, agentes e presos da Central de Polícia, além de pessoas encontradas caídas nas vias públicas (A epidemia da "Grippe”..., 1918a, p. 3). Infelizmente, surgiram casos fatais: "Na Santa Casa falleceram de influenza os doentes Luiz de Souza Romeiro, residente á rua Itapagipe n. 22 e Antonio Torres, portuguez, com 30 annos e residente á rua Marquez de Pombal” (A epidemia da “Grippe”...,1918a, p. 3).

Os relatos revelam que o mal se transmitia em locais compartilhados por 
várias pessoas, convergindo com achados sobre a epidemia em Salvador, na Bahia. Utilizando como fonte a Gazeta Médica, Souza (2007) aponta que os peritos em saúde compreenderam que a transmissão era facilitada onde existiam desde pequenas reuniões até multidões e que, em decorrência, defendiam que esses ambientes públicos ou privados fossem periodicamente desinfetados. Em qualquer lugar onde a moléstia encontrasse facilidade de criar redes de contágio - casas de diversões, teatros, cinemas, mercados, ascensores, bondes, templos, internatos, quartéis, etc. -, cabiam atitudes preventivas.

Além disso, como ratifica a investigação de Bertucci (2018) sobre a história dessa doença na cidade de São Paulo, embasada na análise de textos publicados na imprensa da capital paulista em 1918, a partir de outubro desse ano as notícias sobre a gripe espanhola obtiveram cada vez mais espaço, tanto nos jornais liberais como nos de oposição, construindo uma narrativa cotidiana multifacetada das experiências dos paulistanos, apresentando a epidemia como um drama dividido em distintos atos: negação, aceitação, clímax e alívio pelo fim da doença.

A gripe espanhola se propagou a partir de setembro de 1918, tendo início uma brigada de combate que mobilizou instituições e sujeitos diversos, uma vez que a doença atingia diversos setores da sociedade. No caso do Rio de Janeiro, a ampliação das frentes de ação levou as autoridades a uma série de medidas, entre as quais a criação de postos de hospitalização, por determinação da Comissão Chagas. Detecto, nesse contexto, que, entre as providências sanitárias, consta uma iniciativa sui generis, envolvendo várias escolas numa força-tarefa de luta contra os prejuízos da gripe espanhola. Na sequência, apresento a investigação a respeito, analisando esse fenômeno histórico.

\section{A gripe E AS InStituições ESCOLARES do Rio DE JANEIRo}

Quando a gripe se espalhou, já se sabia que os ambientes nos quais as pessoas permaneciam próximas favoreciam o contágio. Por isso, também as instituições escolares foram encaradas como lugares em que a dispersão da doença era favorecida. E foi sobre esse aspecto que, inicialmente, se falou na imprensa. Uma das primeiras notícias, localizada no Correio da Manhã, é datada de 12 de outubro. Trata do Grupo Escolar Benjamim Constant, em que foram contaminadas nove professoras e algumas alunas, implicando imediata 
redução da frequência discente. A notícia informa que, "Nas escolas Alvaro Batista, Tiradentes, Rivadavia Corrêa, Escola de Applicação e Instituto João Alfredo manifestaram-se tambem varios casos" (Nas escolas municipaes, 1918, p. 3). Nessa mesma edição constam referências à gripe em outras instituições: "Na 4a. escola mixta, no $16^{\circ}$. Districto já se manifestaram nada menos de 70 casos de grippe. A escola [...] foi rigorosamente desinfectada hontem, pela manhã. Na escola de Ricardo Albuquerque verificaram-se tambem vários casos, tendo sido a mesma desinfectada também" (Na 4 a escola..., 1918, p. 3).

Os reportes sobre o adoecimento da população escolar tiveram consequências. No Instituto Profissional João Alfredo, por exemplo, as aulas foram provisoriamente suspensas por uma semana, com o envio dos internos para suas famílias, embora conste que "[...] foram atacados de grippe sessenta e oito alumnos, mas sem gravidade” (O Instituto João Alfredo..., 1918, p. 1). Já na escola Militar do Realengo, a quantidade de casos crescia: "Até hontem pela manhã subia a 160 o numero dos casos de influenza verificados naquelle instituto" (Na escola militar..., 1918b, p. 1).

Diante desses fatos, surgiram notas quanto ao fechamento de escolas: "Na Escola Normal enfermaram muitas alumnas, sendo bem possivel que o governo fluminense ordene o fechamento daquelle estabelecimento de instrucção" (Em Nichteroy, 1918, p. 3). Ao mesmo tempo, avolumavam-se os ataques ao Diretor Geral de Saúde Pública, pois Seidl minimizava o mal que grassava, comparando-o às gripes triviais, utilizando a imprensa para se justificar, diante das imputações de que era alvo. Numa de suas respostas, alegou isenção da responsabilidade sobre o fechamento das escolas, apresentando um telegrama enviado ao Diretor de Higiene, segundo o qual planteava que o grupo médico subordinado àquela repartição poderia instruir melhor qualquer decisão: "Entendo que v. ex. dispondo numeroso corpo de inspectores medicos escolares e tendo ao seu lado director Hygiene municipal não precisa indicações ou conselhos meus questões interesse saude colectividade escolar", e continuando, "Todavia, se a palavra Director Saude Publica Federal é necessária, informo a v. ex. a grande conveniencia da suspensão temporaria dos trabalhos escolares" (O Dr. Carlos Seidl..., 1918, p. 1).

Considerando notícias congêneres, averiguo que as pautas de atenção às escolas foram alimentadas pelo diálogo entre agentes do campo educacional e da área médica. Como exemplo, temos uma exposição que questiona a manu- 
tenção das aulas, associando-a à desinfecção das escolas e condicionando qualquer veredito ao parecer oriundo de uma reunião entre o diretor de Instrução Pública e os membros do serviço de inspeção médica:

[...] o dr. Cicero Peregrino, director da Instrucção Publica, prestou as seguintes informações sobre a epidemia nas escolas:

[...] - que os medicos escolares, a quem compete propor qualquer medida prophylatica, até agora ainda não julgaram necessária a interrupção das aulas;

- que têm sido feitas constantes e repetidas desinfecções nos edificios escolares;

- que, finalmente, hoje, haverá uma reunião de inspectores médicos escolares na qual deverá ser discutido o assumpto amplamente, afim de que sejam assentadas as medidas que as circumstancias impuzerem (O Director da Instrucção..., 1918, p. 3).

No mesmo compasso em que incertezas se configuravam, diversos setores procuravam dar respostas às adversidades. A administração educacional municipal comunicou: "O prefeito manda fechar as escolas publicas, e a Saude Publica, de hoje em deante prestará socorros a domicilio" (A epidemia de “grippe”..., 1918b, p. 1).

Outro anúncio se refere ao fechamento das escolas primárias mantidas pela empresa de serviços marítimos Lloyd, sendo que, nesse caso, há que se considerar que essas unidades educacionais se encontravam disseminadas pelo litoral, especialmente em regiões portuárias. Constam, ainda, notas sobre os impactos da doença no funcionamento de outras instituições, como no Liceu de Artes e Ofícios, na escola paroquial de São José, no Engenho de Dentro e na $3^{\text {a }}$ escola masculina do $3^{\circ}$ Distrito (Varias notas, 1918, p. 3). Ainda sobre os fechamentos, trago os dados da edição de 27 de outubro da folha, que mostram a permanência de medidas restritivas: "O sr. ministro do Interior autorizou aos inspectores do Gymnasios e Escolas Superiores nos Estados, a mandarem fechar esses estabelecimentos no caso de necessidade determinada pela epidemia de influenza" (Fechamento de estabelecimentos de instrucção, 1918, p. 1).

Assinalo outros avisos quanto à suspensão das aulas, neste caso, por tempo indeterminado, que se referem ao Lyceu Rio Branco, ao Instituto Lafayete e ao tradicional Colégio Pedro II. Quanto ao que se noticiou sobre a Escola Militar - onde havia muitos estudantes doentes -, foi transmitido o aviso de que o estabelecimento estava absolutamente impossibilitado de continuar 
atendendo, sendo fechado. Por conseguinte, ficava justificada a licença para que os alunos saudáveis retornassem às suas casas. No entanto, impactante é a revelação de que as salas de aula foram convertidas em enfermarias: "A Escola Militar do Realengo tem sido afetada pelo mal. Há ali uns duzentos alumnos atacados. Os nossos jovens militares estão sendo recolhidos ás salas de aulas, transformadas em enfermarias, por isso que a do estabelecimento já não chega" (A escola militar fechada, 1918a, p. 3).

Mediante essas referências, coloco em destaque a diversidade de instituições educativas atingidas pela epidemia na cidade do Rio de Janeiro, durante os meses finais do ano de 1918. Mas, como se esperava, a Comissão Chagas procurou atuar de modo incisivo no combate à epidemia, apoiada diretamente pela presidência da República. E ressalto que os seus primeiros atos tiveram boa acolhida pela imprensa, especialmente no que diz respeito à instalação de postos de socorros.

Sobre tal fato, destaco a manchete de 23 de outubro, "O presidente da Republica ordenou hontem a installação de novos postos-hospitaes em varios pontos da cidade", que encabeça notas menores cujos títulos são, entre outros, "Os postos creados pela commissão Chagas" e "Soccorros para a população suburbana”. Sob o primeiro título, consta a distribuição das unidades em cinco regiões distintas - Praça 11 de Junho, Ramos, Meyer, Engenho de Dentro e Deodoro -, bem como a relação dos médicos que lá prestariam serviço (Os postos creados pela comissão..., 1918, p. 1). O outro justificava a necessidade de se instalarem os postos em localidades suburbanas: “[...] que os serviços de soccorros fossem intensificados mormente nos subúrbios da Central, onde o numero de doentes é ainda elevado. Por esse motivo, foram enviados varios medicos e remedios para Irajá e Inhauma, Meyer e Piedade" (Soccorros para a população suburbana, 1918, p. 1). Fica sinalizada a preocupação com os mais pobres e desassistidos, o que avalio como positivo, diante das péssimas condições de vida dessa parcela da população à época.

Contudo, o que destaco como absoluta novidade quanto à abertura de postos de socorros é o fato de que significativa parcela dessa estrutura de atendimento sanitário foi instalada em escolas. Vejamos, portanto, o anúncio de transformação nas finalidades sociais das escolas: serviriam como locais de atendimento médico e vacinação. 
Convocados pelo director Geral de Instrucção Publica, os medicos escolares reuniram-se hontem, ficando resolvido [...] o fechamento de todos os estabelecimentos de ensino municipaes.

Os medicos escolares [...] acolheram favoravelmente a idéia de se prestarem a dar consultas nas escolas publicas dos seus respectivos districtos. Nessas consultas, os medicos escolares não só prestarão soccorros aos affectados de "grippe", como farão o serviço de vaccinação e revaccinação, gratuitamente (As escolas publicas fechadas..., 1918, p. 1).

Ratifica esse argumento outra notícia, que comunica a conversão em postos de socorros de todas as unidades escolares vinculadas à Prefeitura, as quais auxiliariam o serviço de saúde federal no atendimento emergencial, caracterizando-se o ambiente escolar como "posto de salvação pública":

\section{O prefeito da cidade resolveu crear em todas as agencias da Prefeitura e em cada uma escola dos districtos, postos de soccorro As providencias do prefeito}

O prefeito, ao chegar hontem, ao seu gabinete, depois de conferenciar com o dr. Manoel Cicero, director de Instrucção, sobre o fechamento por oito dias das escolas publicas, resolveu tomar providencias efficazes para auxiliar a Saude Publica Federal, na emergência actual da epidemia reinante.

S. ex. dirigiu um longo officio urgente, ao ministro da Justiça, communicando-lhe que, á vista da situação de calamidade publica que atravessamos, resolvera crear em todas as agencias da Prefeitura e em cada uma das escolas dos districtos escolares, postos de salvação publica, sob a direcção de todos os medicos da prefeitura, para attender aos pedidos de soccorros (A epidemia de "grippe"..., 1918c, p. 3, grifos do autor).

A política de implantação de postos de socorro, seja nas escolas municipais, seja noutras instalações da cidade, recebeu impulso: "Muitos têm sido os offerecimentos de medicos que foram procurar o prefeito para organizar postos de socorros em diversos pontos da cidade" (Os postos de soccorros municipaes..., 1918, p. 3). Além disso, o diretor da Instrução Pública convidou sete médicos para atuarem no campo educacional: "[...] autorizado pelo prefeito, convidou para auxiliarem o serviço medico escolar, durante a epidemia reinante, os seguintes médicos..." (Para auxiliar o serviço, 1918, p. 3).

Quanto aos “Postos Escolares”, localizei uma relação na qual consta sua 
localização, seus horários de consultas, bem como os nomes de médicos e os endereços das escolas; dados utilizados para se explicitar a instituição onde o atendimento era prestado. Ao examiná-la com minúcia, identifiquei 22 postos de socorros e os horários de consulta respectivos, que variavam entre uma e duas horas, no turno matutino ou vespertino, além de uma nominata na qual aparecem os nomes das escolas "Sarmento" e "Tiradentes", sendo as demais identificadas por denominações como "do largo do Machado", "da rua S. Christovão n. 44", "da estrada da Penha n. 711 (Bomsuccesso)" e "da rua Primeiro de Dezembro n. 9 (Estação Deodoro)" (Os Postos de Soccorros, 1918, p. 1).

Ratifico que uma nova finalidade foi atribuída às escolas durante a epidemia. Isto porque, além da decisão de transformarem instituições escolares em postos de socorros, solicitou-se o protagonismo dos professores. Tal empreendimento requisitou uma ação docente específica, pois envolveu as instituições educativas num audacioso projeto coletivo. Dentre as evidências está uma convocação de inspetores e professoras para reunião destinada a tratar da criação dos postos: "Reunião de professores municipaes": "O director da instrucção publica convocou para hoje, ás três horas da tarde, no salão nobre daquella directoria, uma reunião dos inspectores escolares e professoras cathedraticas, afim de tratar da installação dos postos de soccorros para attender a população infantil” (Reunião de professores municipaes, 1918, p. 1).

A instituição dos postos de socorros em instalações escolares foi uma das principais providências da gestão da capital brasileira no intuito de fazer frente à gripe espanhola. Há, inclusive, anúncios em que dirigentes ofereciam a infraestrutura escolar para aquela nova finalidade, ratificando a centralidade das instituições educativas nesse processo histórico. Em certos casos, utilizando o jornal como forma de contatar a presidência da República: "Um posto na fazenda de Santa Cruz. Recebemos hontem, de Santa Cruz, o seguinte telegramma: 'Queira offerecer ao sr. Presidente da Republica o salão do Gymnasio 24 de fevereiro, para qualquer emergência. - Accacio Barreto'” (Um posto na fazenda de Santa..., 1918, p. 1).

Alguns dos dados mostram que foi gerada uma atuação em rede, envolvendo sujeitos de filiação diversa. É o caso da nota referente à inauguração de um posto de socorro infantil no bairro do Encantado, que passou a atender a partir de 31 de outubro, entre às 8 horas da manhã e às 6 da tarde. Segundo o texto, essa ação concatenou a liderança de duas professoras da rede municipal 
ao apoio de um professor particular, do Comissariado de Alimentação, do monsenhor Rangel (identificado como chefe da Comissão de Socorros da Catedral) e, ainda, de quatro funcionários da Diretoria de Instrução. Além disso, se apelava para a colaboração do comércio local e de qualquer pessoa que pudesse ajudar (Inaugura-se hoje o posto..., 1918, p. 1). Reportes dessa natureza reafirmam o protagonismo do professorado nas respostas à epidemia de gripe espanhola, mediante a sua atuação nas escolas transformadas em postos de socorros. Sublinho, ainda, que a imprensa agiu como apoiadora ao sublinhar a natureza humanitária das atividades dos postos escolares: "Na Escola João Pinheiro, em Madureira, foram distribuídos hontem generos a 2.800 pessoas, que tiveram sete saccos de arroz, sete saccos de assucar, 80 kilos de matte e 2.000 pães" (Na Escola João Pinheiro, 1918, p. 3).

Ademais, a análise de números consecutivos do Correio da Manhã permitiu-me apurar que a rede de postos de socorro escolares foi sendo gradualmente ampliada. Identifico sua atividade em diversas instituições: no Patronato Agrícola de Pinheiro (O Estado Sanitario..., 1918, p. 3); no Liceu de Artes e Ofícios localizado em São José (Posto de soccorros de São..., 1918, p. 3); na rua São Carlos n. 57 - criado pela Diretoria de Instrução Publica e provavelmente sediado na Escola Rivadavia Corrêa, na região do morro de São Carlos, onde existia "imensa pobreza" (O posto de socorro da rua..., 1918, p. 3); na Escola Diogo Feijó, onde "Os soccorros têm sido prestados no posto e a domicilio, pela professora cathedratica D. Alzira C. S. Guimarães, pelas professoras Maria da Gloria Pinto de Moraes e Ainda Ibs Grillo e pelo Sr. Frederico Guimarães" (O posto de soccorros da "Escola...", 1918, p. 3); e na 2a escola masculina do $14^{\circ}$ Districto em Cascadura, tendo sido divulgados os nomes da diretora e das professoras adjuntas, assim como os serviços prestados.

[...] dirigido pela cathedratica da escola Silva Jardim, d. Isaltina de Magalhães Vieira, auxiliada pelas adjuntas Clarice e Arminda dos Santos Nóra, vem prestando importantes serviços e caridade aos [...] attingidos pela gripe. [...] além dos serviços medicos e de informações, o posto vem distribuindo diariamente a mais de 100 pessôas leite, assucar, pão, arroz, mate e café (Posto de soccorro de cascadura, 1918, p. 3).

Na ilha do Bom Jesus, o mérito quanto à instalação do posto de socorro era da professora catedrática Floripes Anglada Lucas. Acrescenta-se à notícia 
que o posto de socorro instalado na escola Afonso Pena, dirigido pelo catedrático Antonio de Souza Cabral, havia atendido 923 pessoas num interstício de apenas três dias, enquanto o da escola Tiradentes atendera a 4.266 "pessoas necessitadas", sob a condução do adjunto Virgilino da Silva Paiva. Sumarizando, o texto enaltece o trabalho desses atores escolares no período de enfrentamento da epidemia de gripe no Rio de Janeiro, tendo como suporte os vários aspectos humanitários elencados: "Em resumo pode-se dizer que o Diretor Geral de Instrucção Publica, auxiliado pelos Inspectores, professores e adjuntos tem estado á altura do calamitoso momento" (Directoria Geral de Instrucção..., 1918, p. 3).

Dentre os postos criados, alguns tinham como foco o atendimento à infância. É o caso do Posto Infantil do Encantado, dirigido pela professora Josephina Montenegro de Andrade, em que a ênfase no atendimento das "creancinhas pobres" é justificada por referências ao princípio cristão da caridade - “[...] amparar as creancinhas desvalidas, muitas delas orphãs, é um gesto de misericordia infinitamente maior" -, reforçado pelos números de atendimento de 601 crianças no próprio posto, e de outras 63, socorridas em suas residências; isso tudo num único dia, em que também foram distribuídos gêneros alimentícios: "[...] para o preparo de caldo em domicilio" (O posto infantil do Encantado, 1918, p. 1).

Cabe lembrar que, entre as instituições da época, eram comuns aquelas voltadas ao público infantil, que, durante a epidemia da gripe espanhola, tiveram suas necessidades aguçadas. Note-se o apelo à assistência feminina na Casa dos Expostos, que, dali por diante, seria remunerada:

[...] onde estão recolhidas muitas creanças, filhas de infelizes victimas da epidemia reinante, apella para as senhoras e senhoritas que quizerem prestar os seus serviços como enfermeiras. As irmãs de caridade já se sentem exhaustas e creanças atacadas da terrível moléstia se vêem quasi sem soccorros. A administração paga generosamente, ás enfermeiras (Um apello da casa..., 1918, p. 1).

Quanto às relações entre a infância brasileira e a epidemia da gripe espanhola, dialogo com a pesquisa sobre a iniciativa das Irmãs de São José, de amparo aos denominados "órfãos da gripe", na cidade de Curitiba. Segundo Bertucci e Silva (2014), essas religiosas fundaram, em $1^{0}$ de janeiro de 1919, o Asilo São Luiz, como resposta aos danos da epidemia aos infantes desampara- 
dos, fornecendo escolarização em nível primário, assim como cursos profissionalizantes de alfaiataria, marcenaria e sapataria.

Em realidade, os números de atendimento divulgados são notáveis. Diariamente, apenas numa escola, eram distribuídos pão e caldo a cerca de 300 pobres. E, visto que recebia donativos da Saúde Pública - geralmente medicamentos diversos, assim como alimentos do Comissariado da Alimentação Pública -, aquele posto de socorros registrou o seguinte movimento de pessoas em 2 de novembro: "Visitas medicas domiciliares, dia 29, 5; dia 30, 8; dia 31, 6; dia $1^{\circ}$., 4. Foram distribuidos soccorros nos dias 29, 30, 31 e $1^{\circ}$., sendo: em medicamentos a 123 pessoas, em mantimentos e outros, a 219 pessoas" (Posto de soccorro da escola..., 1918, p. 1).

Todavia, cabe ainda questionar: diante da instalação dos postos de socorro escolares, que modificaram as finalidades sociais de instituições educativas de diversos tipos, bem como os papéis de atores escolares, o que se obteve? Além disso, quais as providências que determinaram as condições de volta às aulas, de realização de exames e de aprovação dos estudantes?

É interessante compreender-se que as escolas não foram vistas exclusivamente como mais um ambiente onde a gripe espanhola encontrou condições favoráveis para disseminação - mesmo que, nos primeiros dias da pandemia, houvessem sido registrados adoecimentos dentre professores e alunos. Há uma diferença entre o que aconteceu no Rio de Janeiro e em outras cidades. É o que corroboro mediante a pesquisa de Souza (2007), segundo a qual, considerando-se apenas a cidade de Salvador, a gripe atingiu ambientes diversos, entre os quais as escolas - embora essas não tivessem sido incorporadas a quaisquer medidas de prevenção comunitária, à exceção de seu fechamento, dado o elevado percentual de afetados pela doença: "Nos estabelecimentos em que as pessoas conviviam ou trabalhavam muito próximas entre si, [...] como no caso das fábricas, oficinas, escolas, quartéis e estabelecimentos comerciais, a contaminação oscilou entre 42\% e 45\%" (Souza, 2007, p. 186).

Trato agora dos efeitos no trabalho docente, uma vez que diversos professores atuaram na condução dos postos de socorros escolares, coordenando atividades de auxílio à população. Diante desse panorama, entendo que não houve a possibilidade de integralização e avaliação das disciplinas previstas no currículo. Sendo assim, constato o adiamento dos exames finais em algumas instituições: "Como já noticiámos, os exames finaes das escolas publicas serão 
realisados na 2a q quinzena de março" (Os exames finaes..., 1918, p. 3). Já na edição de 6 de dezembro do Correio da Manhã, há publicada uma carta, endereçada aos pais dos alunos pelos diretores do Ginásio Anglo-Brasileiro - escola particular masculina para um seleto alunado internado, que mantinha a Sucursal Fluminense no parque e na Praia do Vidigal, região do Leblon, ofertando os ensinos primário e secundário. A escrita traz as medidas quanto às médias e os exames para a promoção no ano corrente.

Pela primeira vez na historia do Gymnasio foram este anno dispensados os exames finaes e de promoção, sendo adoptada esta medida de excepção em virtude de haverem sido interrompidas as aulas durante a ultima quinzena de outubro, como consequencia inevitavel da epidemia de grippe, que visitou a Capital nesse mez. As promoções serão, pois, feitas, esta vez, pela media annual dos estudos, sendo adoptado, para este fim, o seguinte criterium: a média final de 5 dará direito á promoção, comquanto não haja média inferior a 3 em qualquer materia considerada separadamente. $\mathrm{O}$ alumno que tiver a média inferior a $3 \mathrm{em}$ uma materia, e média geral de 5, poderá della fazer exame a 7 de fevereiro p. f., trazendo declaração escripta do pae ou tutor de havel-a estudado durante as férias. Deverão repetir o anno os que tiverem a média final inferior a 5 e aquelles que a tiverem abaixo de $3 \mathrm{em}$ mais de uma materia (Gymnasio Anglo-brasileiro, 1918, p. 3).

Já na edição de 27 de outubro há notícias quanto ao adiamento dos exames preparatórios e do ensino superior, abordando ainda a concessão de um benefício aos estudantes de medicina que trabalharam na assistência à população durante a epidemia de gripe.

Em vista da situação creada pela epidemia reinante, o dr. Carlos Maximiliano, ministro do Interior, resolveu adiar por um mez as inscripções e o inicio dos exames de preparatorios e das Escolas Superiores: "Os estudantes de medicina que provarem haver trabalhado pelo menos seis dias nos serviços de assistencia mantidos pelo governo, durante a actual epidemia, terão direito a uma época especial de exames, que se realizará dois meses depois das férias regulares." (Adiamento de exames, 1918, p. 1).

Também ocupou espaço a polêmica proposta de isenção de exames dos estudantes do Ensino Superior, que tramitava no Senado e na Câmara. O noticiário menciona um provável veto do presidente da República, em oposição ao qual o estudantado se mobilizou: "[...] os estudantes do Centro Acadêmico 
Nacionalista convocaram para hoje, ás 3 horas da tarde, [...] uma grande reunião" (Os exames por decreto..., 1918, p. 2). Parcela dos alunos não via com bons olhos uma medida legal outorgando a promoção nos exames finais, como evidencia a nota sobre uma reunião da Congregação da Faculdade de Direito de São Paulo, "[...] lamentando que o Congresso Nacional haja votado a referida lei, verdadeiramente subversiva do ensino publico no Brasil” (Uma reunião da congregação da faculdade..., 1918, p. 3).

Também se verificou que, apesar das repercussões da epidemia, atividades de fim de ano - como sessões de encerramento e festividades - foram previstas em algumas instituições; umas em dezembro, outras em janeiro de 1919. O Gymnasio Arte e Instrucção divulgou sua solenidade de encerramento em 3 de janeiro, para a qual estavam previstas a inauguração do quadro dos laureados, a distribuição de prêmios e variadas apresentações artísticas (FESTAS, 1919 , p. 4). Como se aponta, rituais escolares continuaram a integrar a vida institucional, revigorando as confraternizações. Nesse sentido, como pondera Santos (2018), o ritualismo significou a permanência de costumes, regras e práticas constituintes das culturas materiais e simbólicas escolares.

O início de 1919 sediou a reabertura de diferentes instituições. O Atheneu Brasileiro, dedicado ao ensino primário e secundário, e que funcionava com internato e externato, indicou o reinício das aulas para 2 de janeiro, e a mudança para um edifício próprio, "[...] expressamente para o collegio e com todas as condições hygienicas e pedagogicas" (Atheneu Brasileiro, 1919, p. 8). Essa escrita denota a adoção de uma perspectiva higienista, que, no pós-epidemia, inspiraria mais confiança nos serviços educacionais. Por sua vez, o Gymnasio Pio Americano optou por datas distintas: "Reabertura das aulas: curso primario, 15 de janeiro; secundario, 3 de fevereiro" (Gymnasio Pio americano, 1919, p. 8).

A análise das narrativas evidencia conexões com a categoria "temporal", basilar nas pesquisas sobre instituições escolares, pois "[...] define períodos, surgimentos, permanências e extinções relacionados à história da instituição" (Santos; Vechia, 2018, p. 247). E também em razão de que, afetadas no seu funcionamento durante a epidemia, diversas escolas buscaram compensar o período sem aulas, apoiando-se tanto na legislação como em providências internas, procurando suprir carências quanto ao aproveitamento e à avaliação estudantis. 


\section{BONO MALUM SUPERATE, OU VENCER \\ O MAL COM O BEM: CONSIDERAÇÕES FINAIS}

Como defendem Fleck e Anzai (2013, p. 2), na apresentação do dossiê "História da saúde e das doenças: protagonistas e instituições", "Fatos e acontecimentos associados às doenças produzem uma historicidade que se diferencia nas diversas temporalidades e espacialidades". Por conseguinte, quando as doenças são estudadas mediante a aplicação de uma perspectiva histórica, nos avizinhamos da compreensão das estruturas de poder e dos comportamentos humanos, assim como apreciamos, com criticidade, as ações dos diversos grupos sociais numa certa época.

Mediante as análises das notícias do Correio da Manhãa, atentando-se aos referenciais de análise selecionados, é factível concluir-se pela atribuição de novas finalidades sociais a um conjunto de escolas da cidade do Rio de Janeiro durante a epidemia da gripe espanhola de 1918. Do mesmo modo, detecto que outros papéis foram assumidos pelos professores, os quais atuaram nos postos de socorros escolares implementados, entendidos como essenciais no combate à epidemia de gripe espanhola de 1918.

Primeiramente, porque, quando o ser humano está diante da doença, emergem múltiplas preocupações; parte delas conectadas ao medo e à ignorância, as quais nutrem a insegurança e as representações imprecisas, criando-se uma ilusão de distanciamento das reais consequências do mal. Tal argumento é ratificado por Goulart (2005), que, ao investigar os efeitos da gripe espanhola sobre a representação de alguns atores políticos e sociais da cidade do Rio de Janeiro durante a epidemia, conclui que os mesmos embasaram-se no alinhamento entre o higienismo e o processo de modernização social; ambos vistos como fatores de liderança.

Julgo ainda necessário considerar alguns elementos quanto à educação brasileira no período da Primeira República (1889-1930), de modo que se possa caracterizar a organização escolar durante a epidemia da gripe espanhola de 1918. Para tanto, recorro a Nagle (1997), segundo o qual os momentos finais do Império foram marcados por um "fervor ideológico" quanto aos assuntos educacionais e, apesar de filiados a diferentes ideologias, havia grupos que consideravam a necessidade de se avançar na construção de uma política nacional, dada a precariedade do sistema escolar, em todos os seus graus e ramificações. Porém, mesmo existindo uma defesa do caráter central da educação, 
pautada no trinômio "democracia, federação e educação", os ânimos se arrefeceram ao longo dos primeiros anos da era republicana, dando lugar a um clima alheio a discussões e a planos inovadores. No entanto, no decorrer da segunda década do século XX, emergiu um movimento pela difusão da educação, estadualizado, nacionalista e focado na escola elementar; buscando por ideias, planos e soluções quanto à formação necessária ao povo: o entusiasmo pela educação (Nagle, 1997).

Diante disso, entendo que a proposta de transformação de ambientes escolares em postos de socorros para atendimento da população carioca, surgida no contexto das medidas de combate à epidemia adotadas a partir de setembro de 1918, foi, em boa medida, uma estratégia alinhada ao ideário republicano em voga na capital federal. Isto porque se considera a ampliação da atuação regeneradora e civilizatória das escolas, o que foi bem recebido pela sociedade em geral. Afinal, o discurso predominante era de que, por meio da escolarização, crianças e jovens poderiam acessar os caminhos do desenvolvimento e da modernidade e, quiçá, alcançar os meios para serem catapultados a outras camadas sociais.

Se o avanço da epidemia foi, gradativamente, impedindo o funcionamento escolar regular, constato que a audaciosa atribuição de uma nova função às instituições escolares foi uma maneira nobre, eficaz e também compensatória de investimento na educação pública - notadamente no que diz respeito àquilo que se realizou na capital federal -, ação que poderia ser tomada como exemplo para o restante do país.

Ratifico, igualmente, argumentos trazidos por Santos e Vechia (2019), segundo os quais as investigações históricas sobre uma única instituição escolar, ou, em alguns casos, que privilegiam um grupo de estabelecimentos congêneres, têm sido construídas com base na conjugação de escolhas metodológicas diversificadas, que engendram um referente analítico parametrizado pelas categorias espacial, temporal, intelectual, social e política. No caso dessa pesquisa, o aspecto temporal é sublinhado, embora as demais categorias também estabeleçam relações com as análises efetuadas.

Ademais, além de identificar novas perspectivas analítico-interpretativas, que estão sempre mais incorporadas às dinâmicas historiográficas, o estudo em tela mostra o crescente vigor da História de Instituições Escolares, devido ao expressivo número de pesquisas que se ocupam das finalidades sociais e da 
significância das escolas, trazendo à tona o seu impacto formativo. Quer dizer: "Tanto o complexo de finalidades institucionais como a compreensão das significações das diferentes escolas construídas ao longo da história nacional lançam luzes sobre a formação humana, considerando as potencialidades, mas também as críticas ao fazer educacional (re)produtor de desigualdades (Santos; Vechia, 2019, p. 19).

Concluo que os resultados obtidos ressaltam a peculiaridade dos achados e os aspectos prolíficos inerentes. Sublinho, do mesmo modo que Santos e Vechia (2018, p. 1), que "[...] discutir as complexas finalidades sociais e os sentidos da escola no movimento histórico produz novos olhares". As transformações que identifico nas finalidades sociais de instituições escolares, presentes no arco cronológico em que a gripe espanhola atingiu a população carioca, trazem à luz uma resposta histórica à crise social, econômica e política sediada em 1918.

Por fim, ao dialogar com as ponderações de Revel e Peter (1976) sobre a linguagem utilizada para a escrita da história do homem doente e da doença, a compreendo como geradora de um ambíguo sentimento de fascinação e interrogação, aliado, em minha escolha, por um objeto que posiciona a doença como "uma experiência do limite", em que o corpo e as palavras são os sujeitos.

\section{REFERENNCIAS}

NA 4a. ESCOLA mixta. Correio da Manhã, Rio de Janeiro, n. 7168, 12 out. 1918, p. 3. ADIAMENTO DE EXAMES. Correio da Manhã, Rio de Janeiro, n. 7183, 27 out. 1918, p. 1.

UM APELLO DA CASA dos Expostos. Correio da Manhã, Rio de Janeiro, n. 7183, 27 out. 1918, p. 1.

ATHENEU BRASILEIRO. Correio da Manhã, Rio de Janeiro, n. 7252, 4 jan. 1919, p. 8.

PARA AUXILIAR O SERVIÇO medico escolar. Correio da Manhã, Rio de Janeiro, n. 7173, 17 out. 1918 , p. 3.

BARRETO, Maria Renilda Nery. Dar à luz no Rio de Janeiro da Belle Époque: o nascimento das maternidades (1870-1920). In: SANGLARD, Gisele et al. (Orgs.). Filantropos da nação: sociedade, saúde e assistência no Brasil e em Portugal. Rio de Janeiro: Editora FGV, 2015. pp. 185-202.

BASTOS, Maria Helena Camara. Espelho de papel: a imprensa e a história da educação. In: ARAUJO, José Carlos Souza; GATTI JUNIOR, Décio (Orgs.). Novos temas em 
história da educação brasileira: instituições escolares e educação na imprensa. Campinas, SP: Autores Associados; Uberlândia, MG: EDUFU, 2002. pp. 151-174.

BERTUCCI, Liane Maria. Epidemia em papel e tinta: a gripe espanhola nos jornais de São Paulo. Khronos, Revista de História da Ciência, n. 6, pp. 48-58, 2018.

BERTUCCI, Liane Maria; SILVA, Silvana; C. H. Prestes da. A gripe, os órfãos e a educação para o trabalho no asilo São Luiz de Curitiba (1918-1937). Revista Brasileira de História da Educação, Maringá, v. 14, n. 2 (35), pp. 103-133, 2014.

A DEMISSÃO DO DR. SEIDL. Correio da Manhã, Rio de Janeiro, n. 7174, 18 out. 1918, p. 1.

O DIRECTOR DA INSTRUCÇÃO Publica presta informações á imprensa. Correio da Manhã, Rio de Janeiro, n. 7171, 15 out. 1918, p. 3.

DIRECTORIA GERAL DE INSTRUCÇÃO Publica. Correio da Manhã, Rio de Janeiro, n. 7189,2 nov. 1918, p. 3.

O DR. CARLOS SEIDL e as escolas publicas. Correio da Manhã, Rio de Janeiro, n. 7171, 15 out. 1918, p. 1.

A EPIDEMIA DA "GRIPPE”, embora com caracter benigno, não tende ainda a decrescer. Correio da Manhã, Rio de Janeiro, n. 7168, 12 out. 1918a, p. 3.

A EPIDEMIA DE “GRIPPE” continúa a assolar o Rio de Janeiro, tomando as proporções de verdadeiro flagello. Correio da Manhã, Rio de Janeiro, n. 7173, 17 out. 1918b, p. 1.

A EPIDEMIA DE "GRIPPE”. O Prefeito da cidade resolveu crear em todas as agencias da Prefeitura e em cada uma escola dos districtos, postos de soccorro. Correio da Manhã, Rio de Janeiro, n. 7172, 16 out. 1918c, p. 3.

NA ESCOLA JOÃO PINHEIRO. Correio da Manhã, Rio de Janeiro, n. 7187, 31 out. 1918, p. 3.

A ESCOLA MILITAR FECHADA. Correio da Manhã, Rio de Janeiro, n. 7171, 15 out. 1918a, p. 3.

NA ESCOLA MILITAR do Realengo. Correio da Manhã, Rio de Janeiro, n. 7170, 14 out. 1918b, p. 1.

NAS ESCOLAS MUNICIPAES. Correio da Manhã, Rio de Janeiro, n. 7168, 12 out. 1918 , p. 3.

AS ESCOLAS PUBLICAS FECHADAS - Em outros estabelecimentos de ensino. Correio da Manhã, Rio de Janeiro, n. 7172, 16 out. 1918, p. 1.

O ESTADO SANITARIO DO PATRONATO de Pinheiro. Correio da Manhã, Rio de Janeiro, n. 7188, 1 nov. 1918, p. 3.

OS EXAMES FINAES DAS ESCOLAS publicas. Correio da Manhã, Rio de Janeiro, $\mathrm{n}$. 7224, 7 dez. 1918, p. 3.

OS EXAMES POR DECRETO E OS ESTUDANTES. Correio da Manhã, Rio de Janeiro, n. 7226, 9 dez. 1918, p. 2.

FECHAMENTO DE ESTABELECIMENTOS DE INSTRUCÇÃO. Correio da Manhã, Rio de Janeiro, n. 7183, 27 out. 1918, p. 1. 
FESTAS. Correio da Manhã, Rio de Janeiro, n. 7253, 5 jan. 1919, p. 4.

FLECK, Eliane Cristina Deckmann; ANZAI, Leny Caselli. Apresentação do dossiê "História da saúde e das doenças: protagonistas e instituições". Revista Territórios \& Fronteiras, Cuiabá, v. 6, n. 2, pp. 1-6, 2013.

GYMNASIO ANGLO-BRASILEIRO. Correio da Manhã, Rio de Janeiro, n. 7223, 6 dez. 1918, p. 3.

GYMNASIO PIO AMERICANO. Correio da Manhã, Rio de Janeiro, n. 7257, 9 jan. 1919, p. 8.

GOULART, Adriana da Costa. Revisitando a espanhola: a gripe pandêmica de 1918 no Rio de Janeiro. História, Ciências, Saúde - Manguinhos, v. 12, n. 1, pp. 101-142, 2005.

A “GRIPPE” NOS NOSSOS QUARTEIS e o estado sanitario da cidade. Correio da Manhã, Rio de Janeiro, n. 7167, 11 out. 1918a, p. 3.

A “GRIPPE” NOS NOSSOS QUARTEIS e o estado sanitario da cidade. Correio da Manhã, Rio de Janeiro, n. 7165, 9 out. 1918b, p. 3.

INAUGURA-SE HOJE O POSTO infantil do Encantado. Correio da Manhã, Rio de Janeiro, n. 7187, 31 out. 1918, p. 1.

A “INFLUENZA HESPANHOLA" IRROMPEU nos navios brasileiros em operações de guerra. Correio da Manhã, Rio de Janeiro, n. 7148, 22 set. 1918, p. 1.

DOS INFLUENZADOS DO "DEMERARA", dois vieram a fallecer já nesta capital. Correio da Manhã, Rio de Janeiro, n. 7149, 23 set. 1918, p. 3.

O INSTITUTO JOÃO ALFREDO. Correio da Manhã, Rio de Janeiro, n. 7170, 14 out. 1918, p. 1.

OS MARINHEIROS DO “ROYAL TRANSPORT” foram para a Santa Casa. Correio da Manhã, Rio de Janeiro, n. 7161, 5 out. 1918, p. 4.

NAGLE, Jorge. A educação na primeira república. In: HOLLANDA, S. B. História geral da civilização brasileira. Tomo III, v. 2, livro 3, 4. ed., 1997. pp. 261-291.

EM NICHTEROY. Correio da Manhã, Rio de Janeiro, ano XVIII, n. 7171, 15 out. 1918, p. 3.

OS POSTOS CREADOS PELA COMMISSÃO Chagas. Correio da Manhã, Rio de Janeiro, n. 7179, 23 out. 1918, p. 1.

UM POSTO NA FAZENDA DE SANTA Cruz. Correio da Manhã, Rio de Janeiro, n. 7183, 27 out. 1918 , p. 1.

O POSTO INFANTIL DO ENCANTADO. Correio da Manhã, Rio de Janeiro, n. 7190, 3 nov. 1918, p. 1.

OS POSTOS DE SOCCORROS. Correio da Manhã, Rio de Janeiro, n. 7179, 23 out. 1918, p. 1.

O POSTO DE SOCCORROS DA “ESCOLA Diogo Feijó”. Correio da Manhã, Rio de Janeiro, n. 7189, 2 nov. 1918, p. 3.

O POSTO DE SOCCORRO DA RUA S. Carlos. Correio da Manhã, Rio de Janeiro, n. 7189, 2. nov. 1918, p. 3. 
OS POSTOS DE SOCCORROS MUNICIPAES. Correio da Manhã, Rio de Janeiro, $\mathrm{n}$. 7173, 17 out. 1918 , p. 3.

POSTO DE SOCCORRO DA ESCOLA Orsina da Fonseca. Correio da Manhã, Rio de Janeiro, n. 7190, 3 nov. 1918, p. 1.

POSTO DE SOCCORRO DE CASCADURA. Correio da Manhã, Rio de Janeiro, $\mathrm{n}$. 7189, 2 nov. 1918, p. 3.

POSTO DE SOCCORROS DE SÃO José, no edifício do Licêo de Artes e Officios. Correio da Manhã, Rio de Janeiro, n. 7188, 1 nov. 1918, p. 3.

UMA REUNIÃO DA CONGREGAÇÃO DA FACULDADE de Direito de S. Paulo. Correio da Manhã, Rio de Janeiro, n. 7245, 28 dez. 1918, p. 3.

REUNIÃO DE PROFESSORES MUNICIPAES. Correio da Manhã, Rio de Janeiro, $\mathrm{n}$. 7183, 27 out. 1918 , p. 1.

REVEL, Jacques; PETER, Jean-Pierre. O corpo: o homem doente e sua história. In: LE GOFF, Jacques; NORA, Pierre. História: novos objetos. Rio de Janeiro: Francisco Alves, 1976. pp. 141-159.

SANTOS, Ademir Valdir dos. Ritualismo e nacionalização da escola primária em Santa Catarina (anos 1940). Educação em Questão, Natal, v. 56, n. 49, pp. 196-224, 2018. SANTOS, Ademir Valdir dos; VECHIA, Ariclê. A pesquisa sobre instituições escolares na Revista Brasileira de História da Educação (2001-2016). Cadernos de Pesquisa, São Luís, v. 25, n. 4, pp. 245-266, 2018.

SANTOS, Ademir Valdir dos; VECHIA, Ariclê. As escolas que construímos: a história de instituições escolares na Revista Brasileira de História da Educação. Revista Brasileira de História da Educação, v. 19, pp. 1-26, 2019.

SOCCORROS PARA A POPULAÇÃO SUBURBANA. Correio da Manhã, Rio de Janeiro, n. 7179, 23 out. 1918, p. 1.

SOUZA, Christiane Maria Cruz de. A gripe espanhola na Bahia: saúde, política e medicina em tempos de epidemia. Tese (Doutorado em História das Ciências da Saúde) - Programa de Pós-Graduação em História das Ciências e da Saúde, Casa de Oswaldo Cruz - Fundação Oswaldo Cruz, Rio de Janeiro, 2007. 387 pp.

AS VICTIMAS DA GRIPPE. Informações prestadas á Camara. Correio da Manhã, Rio de Janeiro, n. 7241, 24 dez. 1918, p. 3.

VARIAS NOTAS. Correio da Manhã, Rio de Janeiro, n. 7171, 15 out. 1918, p. 3.

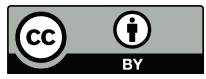

Artigo submetido em 18 de novembro de 2020. Aprovado em 22 de abril de 2021. 